\title{
Etanercept Increases Bone Mineral Density in Ankylosing Spondylitis, but Does Not Prevent Vertebral Fractures: Results of a Prospective Observational Cohort Study
}

\author{
Maria A.C. van der Weijden, J. Christiaan van Denderen, Willem F. Lems, \\ Michael T. Nurmohamed, Ben A.C. Dijkmans, and Irene E. van der Horst-Bruinsma
}

ABSTRACT. Objective. Ankylosing spondylitis (AS) is characterized by chronic inflammation leading to ankylosis, but also to low bone mineral density (BMD) and vertebral fractures (VFx). Treatment with tumor necrosis factor- $\alpha$ blockers decreases inflammation and has shown to be effective in increasing BMD. We studied the effects of etanercept (ETN) on BMD and VFx in patients with AS after 2 years of treatment. Further, we studied changes in bone turnover markers and radiological damage.

Methods. Patients with active AS, treated with ETN for 2 years, were included. BMD lumbar spine and hip were measured at baseline and after 2 years, as well as radiological damage (modified Stoke Ankylosing Spondylitis Spinal Score with the addition of the thoracic spine), VFx (Genant method), and change in bone turnover markers.

Results. Forty-nine patients with AS were included. After 2 years of ETN, hip BMD increased by $2.2 \%(\mathrm{p}=0.014)$ and lumbar spine BMD by $7.0 \%(\mathrm{p}<0.001)$. The Bath Ankylosing Spondylitis Disease Activity Index decreased significantly $(\mathrm{p}<0.001)$, as well as C-reactive protein and erythrocyte sedimentation rate $(\mathrm{p}<0.001)$. Despite ETN therapy, the number of patients with VFx more than doubled (from 6 to 15 patients, $p=0.003$ ). Also, the radiological damage increased significantly over time (from 12.1 to $18.5, \mathrm{p}<0.001$ ); however, no significant change in bone turnover markers was found.

Conclusion. This prospective longitudinal observational cohort study showed that after 2 years of ETN, BMD of the hip and spine increased significantly, but the number of patients with VFx and the severity of VFx increased as well. Besides that, radiological progression, including the thoracic spine, increased significantly. Thus, the favorable bone-preserving effect is accompanied by unfavorable outcomes on VFx and radiological damage. (First Release February 15 2016; J Rheumatol 2016;43:758-64; doi:10.3899/jrheum.150857)

Key Indexing Terms:

ANKYLOSING SPONDYLITIS

BONE MINERAL DENSITY VERTEBRAL FRACTURES RADIOLOGICAL DAMAGE BONE TURNOVER MARKERS

From the Department of Rheumatology, VU University Medical Center; Department of Rheumatology, Jan van Breemen Research Institute/Reade, Amsterdam, the Netherlands.

This investigator-initiated cohort study was financed by an unrestricted grant from Pfizer.

M.A. van der Weijden, $M D, M S c, P h D$, Department of Rheumatology, VU University Medical Center, and Department of Rheumatology, Jan van Breemen Research Institute/Reade; J.C. van Denderen, $M D, P h D$, Department of Rheumatology, Jan van Breemen Research Institute/Reade; W.F. Lems, MD, Professor, Department of Rheumatology, VU University Medical Center, and Department of Rheumatology, Jan van Breemen Research Institute/Reade; M.T. Nurmohamed, MD, Professor, Department of Rheumatology, VU University Medical Center, and Department of Rheumatology, Jan van Breemen Research Institute/Reade; B.A. Dijkmans, $M D$, Professor, Department of Rheumatology, VU University Medical Center; I.E. van der Horst-Bruinsma, $M D, P h D$, Department of Rheumatology, VU University Medical Center, and Department of Rheumatology, Jan van Breemen Research Institute/Reade.

Address correspondence to Dr. M.A. van der Weijden, Department of Rheumatology, VU University Medical Center, Room 3A-54, P.O. Box 7057, 1007 MB Amsterdam, the Netherlands.

E-mail:mac.vanderweijden@vumc.nl

Accepted for publication December 15, 2015.
Ankylosing spondylitis (AS) is characterized by chronic inflammation leading to ankylosis of the spine and sacroiliac joints. Bone loss is a well-known complication of $\mathrm{AS}^{1,2}$. Bone loss is highly prevalent after long disease duration, but starts at an early stage ${ }^{3,4}$. Bone loss and inflammation are probably responsible for the occurrence of vertebral fractures (VFx) in this patient group $5,6,7,8$. The pathogenesis of the decrease in bone mineral density (BMD) is complex. Persistent inflammation [by inflammatory cytokines such as tumor necrosis factor- $\alpha$ (TNF- $\alpha)$ ] might be an important etiologic factor ${ }^{9,10}$.

One way to decrease inflammation is treatment with TNF- $\alpha$ blockers. In rheumatoid arthritis (RA), this therapy reduced disease activity and radiographic progression by reducing inflammation, and it was shown to increase $\mathrm{BMD}^{11,12,13}$. Also in AS, many studies have shown the effects of TNF- $\alpha$ blockers on inflammation by decreasing disease activity, although effects on decreasing radiographic progres- 
sion are disappointing ${ }^{14,15}$. Considering effects of TNF- $\alpha$ blockers on BMD, patients treated with infliximab showed significant increases in BMD scores over 2 years ${ }^{16}$. A very small study $(\mathrm{n}=10)$ by Marzo-Ortega, et al showed that etanercept (ETN) increased BMD in a short followup study of 6 months ${ }^{17}$. Arends, et al also showed an increase in BMD and an effect in favor of bone formation by measuring bone turnover markers in patients treated with different types of TNF- $\alpha$ blockers ${ }^{18}$, but whether there were differences between the effects of TNF- $\alpha$ blockers is not clear. Further, clinically relevant outcome measures such as VFx, radiographic progression, and disease activity combined in 1 study were not performed.

Therefore, the aim of our study was to measure the effects of 2 years of ETN on bone quality by measuring change of BMD and the incidence of VFx. Further, we assessed changes in bone turnover markers and the effects on radiographic damage.

\section{MATERIALS AND METHODS}

Study population. Patients with AS who fulfilled the modified New York criteria for AS and were eligible for treatment with anti-TNF- $\alpha$ (ETN) according to the Assessment of Spondyloarthritis international Society (ASAS) guidelines were recruited from the Jan van Breemen Research Institute/Reade, a large outpatient rheumatology center in Amsterdam, the Netherlands ${ }^{19}$. The data for our open prospective followup study were collected systematically every 3 months during the first year, and twice yearly thereafter.

Patients with AS were treated during 2 years as decided by their physician with ETN ( $25 \mathrm{mg}$ twice a week or $50 \mathrm{mg}$ once a week) if they had previously failed treatment with at least 2 nonsteroidal antiinflammatory drugs and if they had active disease [Bath Ankylosing Spondylitis Disease Activity Index $(\mathrm{BASDAI}) \geq 4$ ]. Patients who previously received another anti-TNF agent were excluded from our study.

Demographic data, such as HLA-B27 status, extraarticular manifestations, current use of medication including antiosteoporotic drugs, as well as data on known risk factors for osteoporosis, such as age, sex, race, smoking, disease duration, and comorbidities were collected at baseline.

The protocol was approved by the local Medical Ethics Committee and all patients provided written informed consent.

Bone mineral density. First, the change in BMD of the lumbar spine (L2-L4) and left hip (total proximal femur) after 2 years of ETN was investigated. Each patient was measured by dual-energy x-ray absorptiometry (DEXA) using Lunar (Lunar expert DPX-IQ, Oldelft). Results were presented as $\operatorname{BMD}\left(\mathrm{g} / \mathrm{cm}^{2}\right), \mathrm{T}$ scores, and $\mathrm{Z}$ scores. The T score corresponds to the number of SD from the normal mean obtained from young healthy adults and the $\mathrm{Z}$ score is the T score with a correction for age. Osteopenia and osteoporosis are defined according to the World Health Organization: (1) osteoporosis ( $\mathrm{T}$ score $\leq-2.5$ in spine and/or hip), and (2) osteopenia $(-2.5<\mathrm{T}$ score $<-1.0$ in spine and/or hip without osteoporosis) ${ }^{20}$.

Vertebral fractures. Further, we investigated the occurrence of VFx. Radiographs of thoracic and lumbar spine were made at baseline and after 24 months. The lateral radiographs were evaluated chronologically for VFx by 2 experienced investigators (WL, BD) who were blinded for medication the patients received. Vertebral deformities were determined by grading each vertebral body (T4-L5) according to the Genant criteria for fractures ${ }^{21}$. In Genant's semiquantitative assessment, the vertebrae receive a severity grade based on the visually apparent degree of vertebral height loss. The reduction in height is divided in grades on a scale of 0-3: grade 0 (normal) represents a reduction in anterior, middle, and/or posterior vertebral heights of $<20 \%$; grade 1 (mild) represents a reduction of 20\%-25\%; grade 2 (moderate) reduction of $25 \%-40 \%$; and grade 3 (severe) more than $40 \%$ reduction. VFx were defined as a reduction of $\geq 20 \%$ of the vertebral body height ${ }^{21}$.

Markers of bone turnover. Several bone turnover markers including C-telopeptides of Type I collagen (CTX-I), C-telopeptides of Type II collagen (CTX-II), receptor activator of nuclear factor- $\mathrm{\kappa B}$ ligand (RANKL), osteoprotegerin (OPG), and osteocalcine were obtained at $0,3,6$, and 12 months. Nonfasting serum and urine were collected and stored at $-20^{\circ} \mathrm{C}$ until analyses. Bone resorption was measured by CTX-I and CTX-II. CTX-I was determined by $\beta$-isomerized carboxy terminal telopeptide of Type I collagen in serum using commercial assays according to the instructions of the manufacturer (Roche Diagnostics). CTX-II was determined using a urine Cartilaps ELISA (from Immunodiagnostic Systems; IDS) for the quantification of degradation products of C-terminal telopeptides of Type II collagen in human urine. Levels of osteoclast-regulating proteins, including total RANKL and OPG, were determined in serum using an ELISA (from Immundiagnostik AG). Bone formation was measured by osteocalcin using commercial assays according to the instructions of the manufacturer (Roche Diagnostics). All assays on the analyzer had an intraassay and interassay coefficient of variation of $\leq 5 \%$. The ELISA had an intraassay and interassay coefficient of variation of $\leq 10 \%$.

Radiographic damage. The degree of radiological damage of the spine before and after treatment with ETN was determined with the modified Stoke Ankylosing Spondylitis Spine Score (mSASSS), an index of radiological damage of the cervical and lumbar spine ${ }^{22}$. The lateral radiographs of the spine of each patient were examined by 2 experienced investigators $(\mathrm{CvD}$, $\mathrm{IvdH})$ at baseline and after 24 months. Additionally, the radiographs of the thoracic spine were assessed as well (T9-T12), although they were not implemented in the official scoring method of the mSASSS. However, because the low thoracic spine might have an additive effect on the sensitivity to change $\mathrm{e}^{23}$ (although not validated for it yet), and it is a common place for VFx, the radiographs were included in the measurement.

Disease activity. Disease activity measures included the disease activity score BASDAI ${ }^{24}$, whereby the functional capacity scores of the Bath Ankylosing Spondylitis Functional Index ${ }^{25}$ and the Bath Ankylosing Spondylitis Metrology Index ${ }^{26}$ measured the physical function. The ASAS Working Group criteria for response were applied to define response ${ }^{27}$ as a $50 \%$ improvement or as an absolute improvement of 2 points of the BASDAI (0-10 scale), and an expert opinion in favor of continuation of treatment after 3 months.

Statistical analysis. Categorical variables were calculated as frequencies and percentages. Continuous variables were reported as mean and SD or, when skewed, as median and interquartile range. To examine the longitudinal changes in BMD (and T scores and Z scores), BMD was first tested for normality (with the Shapiro-Wilks test), and subsequently the paired Student $\mathrm{t}$ test or Wilcoxon signed-rank test. Differences in VFx were tested with the $\mathrm{McNemar}$ test. Bone turnover markers were tested for a linear trend with regression analyses. To detect differences between different time moments, the Friedman test was used. Radiological damage was analyzed first by testing for normality, and subsequently the change over time was tested with the nonparametric Wilcoxon signed-rank test. Disease activity changes in the BASDAI, C-reactive protein (CRP), and erythrocyte sedimentation rate (ESR) were also analyzed with the nonparametric Wilcoxon signed-rank test because of the skewed distribution.

Statistical analyses were performed with SPSS statistical software, version 20.0 (SPSS). P values $<0.05$ were considered significant.

\section{RESULTS}

Patient characteristics. In total, 49 patients with AS were enrolled and monitored after starting with ETN. The mean followup duration of these patients was 2.3 years. The baseline demographics and clinical features are shown in Table 1 . Most patients were men $(82 \%)$, the mean age was

Personal non-commercial use only. The Journal of Rheumatology Copyright @ 2016 . All rights reserved. 
Table 1. Baseline characteristics of the AS-etanercept cohort $(n=49)$. Values are mean (SD) or median (interquartile range) unless otherwise specified.

\begin{tabular}{|c|c|}
\hline Characteristics & Values \\
\hline \multicolumn{2}{|l|}{ Demographic variables } \\
\hline Men, n $(\%)$ & $40(81.6)$ \\
\hline Age, yrs & $41.8(9.2)$ \\
\hline White, n (\%) & $38(77.6)$ \\
\hline \multicolumn{2}{|l|}{ Disease-related variables } \\
\hline Disease duration, yrs & $12.2(9.1)$ \\
\hline Symptom duration, yrs & $15.8(9.9-23.4)$ \\
\hline Followup duration, yrs & $2.3(0.7)$ \\
\hline HLA-B27 positivity, n (\%) & $43(87.8)$ \\
\hline $\mathrm{ESR},<20 \mathrm{~mm} / \mathrm{h}$ & $20.0(6.0-39.0)$ \\
\hline $\mathrm{CRP},<10 \mathrm{mg} / 1$ & $14.0(3.0-39.0)$ \\
\hline BASDAI, 0-10 & $5.7(1.6)$ \\
\hline BASFI, 0-10 & $5.7(2.1)$ \\
\hline BASMI, 0-10 & $4.4(2.3)$ \\
\hline History of uveitis, n (\%) & $17(34.7)$ \\
\hline History of psoriasis, $\mathrm{n}(\%)$ & $6(12.2)$ \\
\hline History of IBD, n (\%) & $3(6.1)$ \\
\hline History of peripheral arthritis, n (\%) & $16(32.7)$ \\
\hline \multicolumn{2}{|l|}{ Radiographic damage } \\
\hline Total mSASSS, $0-72$ & $10.0(3.8-35.5)$ \\
\hline Total mSASSS + ThSpine, 0-90 & $12.1(6.8-42.7)$ \\
\hline \multicolumn{2}{|l|}{ BMD-related variables } \\
\hline $\mathrm{BMI}, \mathrm{kg} / \mathrm{m}^{2}$ & $26.3(3.4)$ \\
\hline Menopausal status, n (\%) & $2(4.1)$ \\
\hline 1 or more prevalent $\mathrm{VFx}, \mathrm{n}(\%)$ & $6(12.2)$ \\
\hline Smoking, current, n (\%) & $24(49.0)$ \\
\hline \multicolumn{2}{|l|}{ BMD variables } \\
\hline BMD hip & $0.903(0.152)$ \\
\hline BMD L2-L4 & $1.141(0.203)$ \\
\hline T score hip & $-0.92(1.14)$ \\
\hline T score L2-L4 & $-0.29(1.77)$ \\
\hline Z score hip & $-0.81(1.04)$ \\
\hline Z score L2-L4 & $-0.31(1.71)$ \\
\hline \multicolumn{2}{|l|}{ Medication } \\
\hline NSAID, current, n (\%) & $49(100)$ \\
\hline DMARD, current, n (\%) & $12(24.5)$ \\
\hline Corticosteroids, current, n (\%) & $1(2.0)$ \\
\hline Bisphosphonates, current, n (\%) & $3(6.1)$ \\
\hline
\end{tabular}

AS: ankylosing spondylitis; ESR: erythrocyte sedimentation rate; CRP: C-reactive protein; BASDAI: Bath AS Disease Activity Index; BASFI: Bath AS Functional Index; BASMI: Bath AS Metrology Index; IBD: inflammatory bowel disease; mSASSS: modified Stoke Ankylosing Spondylitis Spine Score; ThSpine: thoracic spine; BMD: bone mineral density; BMI: body mass index; VFx: vertebral fractures; NSAID: nonsteroidal antiinflammatory drug; DMARD: disease-modifying antirheumatic drug.

42 years, and the mean disease duration was 12.2 years. Three patients had a bilateral total hip replacement at inclusion. There was a high disease activity before start of therapy and the majority responded well.

Bone mineral density. All 49 patients had 2 DEXA scans of the spine and 46 patients had a DEXA of the hip (3 patients had a bilateral hip replacement). At baseline, $12 \%$ of the patients had osteoporosis, $45 \%$ osteopenia, and $43 \%$ had a normal BMD. After 2 years of ETN, this changed to $4 \%$ osteoporosis, $41 \%$ osteopenia, and 55\% normal BMD (Table 2).
After 2 years of treatment, hip BMD increased significantly by $2.2 \%$ (5.7), $\mathrm{p}=0.014$, and lumbar spine BMD increased significantly by $7.0 \%(9.5), \mathrm{p}<0.001$. The mean $\mathrm{T}$ scores and $\mathrm{Z}$ scores showed the same significant increase of the hip ( $\mathrm{p}=$ 0.037 vs $\mathrm{p}=0.002$ ) and lumbar spine (both $\mathrm{p}<0.001$ ).

Vertebral fractures. At baseline, 6 patients (12.2\%) already had at least $1 \mathrm{VFx}$. After 2 years of ETN, the number of patients with 1 or more VFx more than doubled to 15 patients (30.6\%; $p=0.003$; Table 3). All fractures were wedge deformities and most VFx were localized in the (mid)thoracic spine (Figure 1). Not only did the number of patients with VFx increase significantly over 2 years $(\mathrm{p}=0.004)$, but also the severity (grade) of the VFx, from 4 fractures (out of 8) graded 2 or more to 13 fractures (out of 21) graded at least 2 (Table 3). Analyses for risk factors for the development of VFx did not show any variable to be associated with these incident VFx (such as age, BMD, disease activity, radiological damage; data not shown).

Markers of bone metabolism. Boxplots of the distribution of bone turnover markers over time as well as the change in disease activity (BASDAI) and inflammation (CRP) are shown in Figure 2. Bone turnover markers were tested for linear trend with regression analyses, but there was no significant trend over time for the bone "resorption" markers, the "osteoclast-regulation" markers, or for the bone "formation" marker. To detect differences between different time moments, the Friedman test was used. No significant changes in bone turnover markers were detected over time, except for OPG (which showed a decreasing trend). However, the RANKL/OPG ratio did not change significantly over time.

Radiological damage. The median radiological damage (total mSASSS score) at baseline was 10.0 (3.8-35.5) and increased after 2 years to $15.5(5.5-42.5)$. The total mSASSS + ThSpine (thoracic spine) had a median at baseline of 12.1 (6.8-42.7) and progressed to 18.5 (8.7-52.0). There was a significant difference between the radiological damage at baseline and after 2 years $(p<0.001)$ measured by the mSASSS and the mSASSS + ThSpine. Correlation tests did not show a significant relation between BMD change over time and the radiological progression. Further, there was no correlation between bone turnover markers and radiological progression or between disease activity variables and radiological progression.

Disease activity. Disease activity measured by the BASDAI decreased from $5.8(5.1-6.8)$ at baseline to $2.1(1.0-4.1)$ after 12 months and to $2.8(1.0-4.4)$ after 24 months ( $p<0.001$ at all timepoints compared with baseline). According to the ASAS major clinical response criteria, $85 \%$ of the patients responded to ETN at 3 months, $69 \%$ at 12 months, and $63 \%$ at 24 months.

Disease activity measured by inflammation markers such as CRP and ESR also decreased significantly ( $p<0.001$ at all timepoints compared with baseline). CRP decreased from

Personal non-commercial use only. The Journal of Rheumatology Copyright $\subset$ $\subset$ 2016. All rights reserved 
Table 2. BMD measurement at hip and spine. Normal BMD $=\mathrm{T}$ score $\geq-1.0$, osteopenia $=-2.5<\mathrm{T}$ score $<-1.0$, and osteoporosis $=\mathrm{T}$ score $\leq-2.5$. Values are $\mathrm{n}(\%)$.

\begin{tabular}{|c|c|c|c|c|c|c|}
\hline \multirow[t]{2}{*}{ Measurements } & \multicolumn{3}{|c|}{$\mathrm{t}=0 \mathrm{Yr}$, before ETN } & \multicolumn{3}{|c|}{$\mathrm{t}=2$ Yrs, after ETN } \\
\hline & Hip* & Spine & Total BMD & Hip*广 & Spine & Total BMD \\
\hline Normal BMD & $23(46.9)$ & $29(59.2)$ & $21(42.9)$ & $27(55.1)$ & $36(73.5)$ & $27(55.1)$ \\
\hline Osteoporosis & $4(8.2)$ & $6(12.2)$ & $6(12.2)$ & $2(4.1)$ & $1(2)$ & $2(4.1)$ \\
\hline
\end{tabular}

$*$ Calculated in 46 patients because 3 patients had a bilateral hip replacement. ${ }^{\dagger}$ Change of BMDhip, $\mathrm{p}=0.014 .{ }^{\ddagger}$ Change of $\mathrm{BMDspine}, \mathrm{p}<0.001$. $\mathrm{BMD}$ : bone mineral density; ETN: etanercept; total BMD: BMD hip and spine.

Table 3. VFx before and after ETN in ankylosing spondylitis $(\mathrm{n}=49)$. Values are $\mathrm{n}(\%)$ unless otherwise specified.

\begin{tabular}{|c|c|c|c|c|}
\hline \multirow[t]{2}{*}{ VFx } & \multicolumn{2}{|c|}{$\mathrm{t}=0 \mathrm{Yr}$ before ETN } & \multicolumn{2}{|c|}{$\mathrm{t}=2$ Yrs after ETN } \\
\hline & $\begin{array}{l}\text { Patients } \\
\text { with VFx }\end{array}$ & No. VFx & $\begin{array}{l}\text { Patients } \\
\text { with VFx }\end{array}$ & No. VFx \\
\hline $0 \mathrm{VFx}$ & $43(87.8)$ & & $34(69.4)$ & \\
\hline $1 \mathrm{VFx}$ & $4(8.2)$ & & $9(18.4)$ & \\
\hline Grade I & & 2 & & 5 \\
\hline Grade II & & 2 & & 4 \\
\hline Grade III & & 0 & & 0 \\
\hline $2 \mathrm{VFx}$ & $2(4.1)$ & & $6(12.2)$ & \\
\hline Grade I & & 2 & & 3 \\
\hline Grade II & & 2 & & 7 \\
\hline Grade III & & 0 & & 2 \\
\hline Total no. VFx & & $8(16.3)$ & & $21(42.9)^{*}$ \\
\hline $\begin{array}{l}\text { Total patients } \\
\text { with VFx }\end{array}$ & $6(12.2)$ & & $15(30.6)^{* *}$ & \\
\hline
\end{tabular}

$* \mathrm{p}=0.004$ for change of total number of VFx. ** $\mathrm{p}=0.003$ for change of total patients with VFx. VFx: vertebral fracture; ETN: etanercept; grade I: reduction of vertebral height $20 \%-25 \%$; grade II: reduction of vertebral height $25 \%-40 \%$; grade III: reduction of vertebral height $>40 \%$.
$14.0(3.0-39.0)$ at baseline to $2.0(1.0-6.0)$ at 12 months. ESR decreased from $20.0(6.0-39.5)$ at baseline to $5.0(2.0-9.0)$ at 12 months. ESR and CRP changes were strongly correlated $(\mathrm{p}<0.001)$.

There was a significant relationship between the change in hip and spine BMD and the change in inflammation markers (i.e., ESR and CRP) over 12 months. The decrease in ESR and CRP were significantly associated with the increase in hip and spine BMD ( $\triangle \mathrm{BMD}$ hip: $\mathrm{p}=0.040$ vs $\mathrm{p}=0.005$, and $\triangle \mathrm{BMD}$ spine: $\mathrm{p}=0.012$ vs $\mathrm{p}<0.001)$.

\section{DISCUSSION}

Our prospective observational cohort study in patients with active AS showed that after 2 years of TNF- $\alpha$ blocking therapy with ETN, BMD of the hip as well as BMD of the spine increased significantly, but also the number and severity of VFx and radiographic damage increased as well. This observation suggests that despite the decrease in inflammation and increase in the amount of bone, the anticipated increase in bone quality does not occur. In addition, the ongoing bony proliferation is also unfavorable, which emphasizes that despite TNF- $\alpha$ blockers, bone (patho)physiology is still not optimal.

Because persistent inflammation might be an etiological factor of bone loss in AS, anti-TNF- $\alpha$ therapy has been

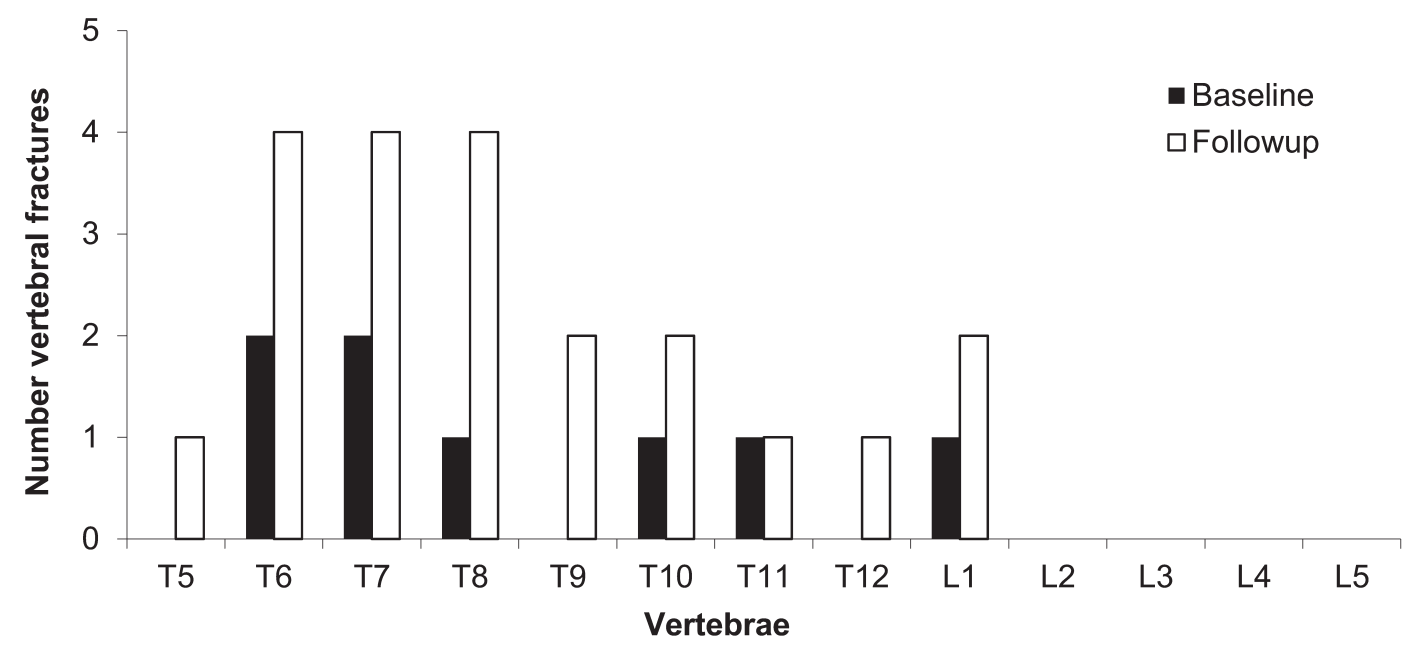

Figure 1. Location of vertebral fractures before and after etanercept in ankylosing spondylitis.

Personal non-commercial use only. The Journal of Rheumatology Copyright $\subset$ 2016. All rights reserved. 

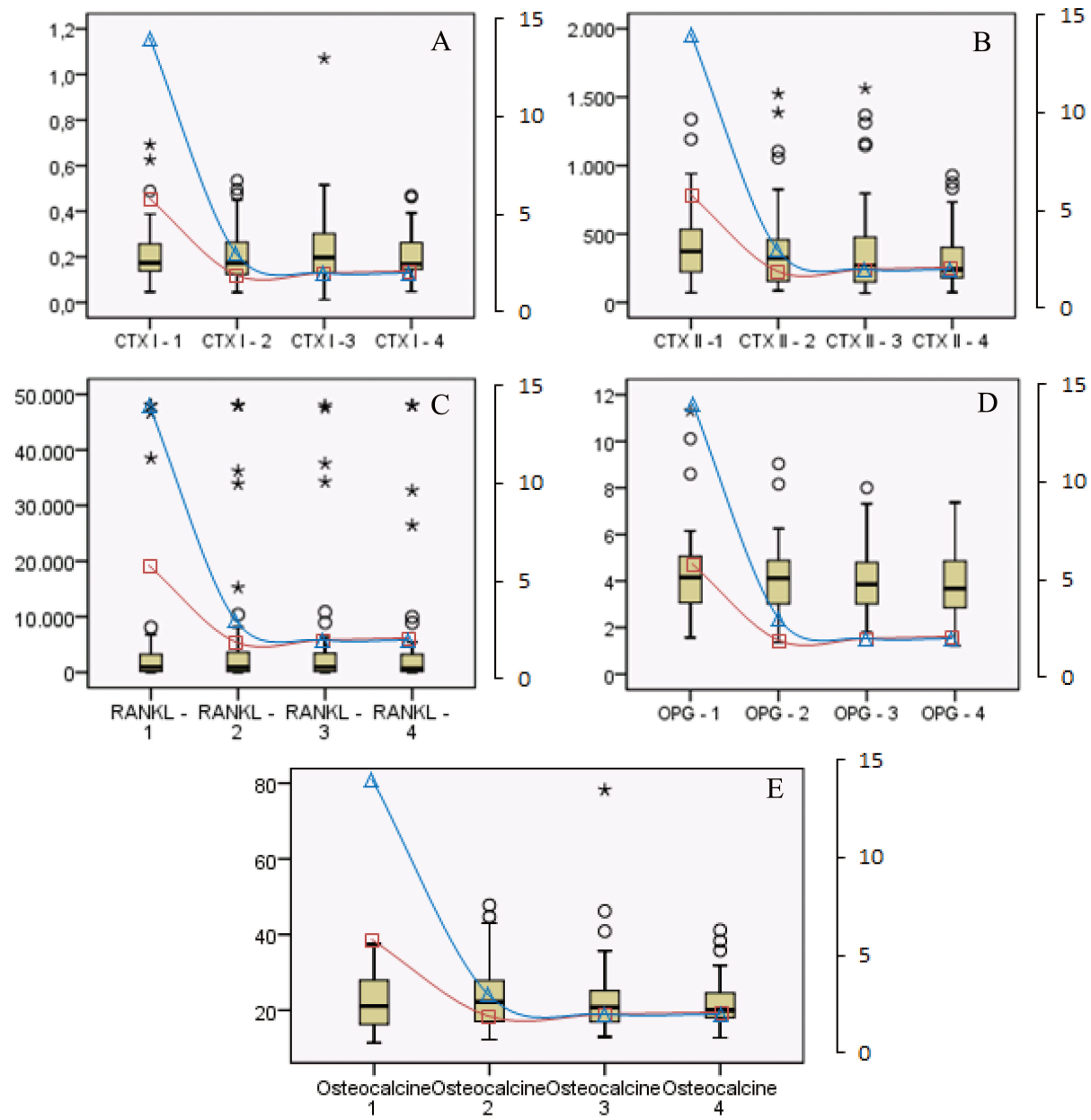

Figure 2. Distribution of bone turnover markers during treatment with etanercept. Vertical scale left: scale of different bone markers. Vertical scale right: scale of Bath Ankylosing Spondylitis Disease Activity Index (BASDAI) and C-reactive protein (CRP). Horizontal: $1=0$ months; $2=3$ months; $3=6$ months; $4=12$ months. Red boxes indicate BASDAI. Blue triangles indicate CRP. CTXI: C-telopeptides of Type I collagen; CTXII: C-telopeptides of Type II collagen; RANKL: receptor activator of nuclear factor-kB ligand; OPG: osteoprotegerin.

proposed as treatment that controls inflammation with subsequent prevention of osteoporosis and associated $\mathrm{VFx}^{28,29}$. Our study showed that after 2 years of ETN, the BMD increased significantly in the lumbar spine as well as in the hips. This finding is in concordance with other studies that also showed an increasing trend in BMD after treatment with TNF blockers $16,18,30,31,32$.

Strikingly, to our knowledge, ours is the first study that describes the rapid progression of the number and severity of VFx over 2 years, despite lowering disease activity and inflammation through ETN therapy and despite the increase of BMD. The interpretation of VFx in AS is a challenge because the method of Genant does not differentiate between AS-related deformities, degenerative changes, or osteoporotic fractures. The presence of low BMD and the localization of the VFx suggest that these fractures are "real" osteoporotic fractures. We have earlier documented in a cohort of patients with early spondyloarthropathies a high number of patients (15\%) with VFx, especially in the thoracic spine $^{7}$, and advised to include the whole spine when taking radiographs to followup the patients. Unfortunately, VFx in AS are often missed in clinical routine procedures; however, diagnosing these fractures is important because the knowledge of existing fractures is necessary for optimal assessment of risk for future fractures and treatment ${ }^{6,33}$. However, to date there are no clear guidelines for how we should treat these patients. In our study, the treatment of the osteopenic/osteoporotic patients was performed by the treating rheumatologist. All patients were treated with calcium/vitamin D, and no bisphosphonate treatment was started in the period of the study.

The increased prevalence of VFx despite the increase of BMD suggests that it is more likely that despite the increase in quantity of bone mass, the problem in $\mathrm{AS}$ is more a result of a decrease in bone quality. A specific definition of the quality of bone is problematic because multiple factors

Personal non-commercial use only. The Journal of Rheumatology Copyright ()$^{2016}$. All rights reserved. 
contribute to the structural integrity of bone: not only the total bone mass, but also bone geometry and properties of constituent tissue ${ }^{34}$. Because BMD has been shown to be a limited predictor of fracture risk ${ }^{35}$, more clinical interest is now needed for complementary measures of bone quality that could improve fracture risk prediction ${ }^{36}$. One of these measures could have been bone turnover markers, but unfortunately we did not find a linear trend of bone "resorption" markers (CTX-I, CTX-II), "osteoclast-regulating” markers (RANKL, OPG), or of the bone "formation" marker (osteocalcin) over time during ETN treatment, whereas the inflammatory variables (CRP and ESR) and disease activity responded well. A decrease in bone resorption markers and osteoclast-regulating markers was therefore expected alongside an increase in the bone formation marker ${ }^{13,16,18}$. Still, our results were in line with the study of Allali, et al who also found in 29 patients with AS an increase in BMD during treatment with TNF- $\alpha$ blockers and no change in biochemical markers (osteocalcin and total deoxypyridinoline) ${ }^{30}$. However, an early increase after 2-12 weeks in markers of bone formation (bone alkaline phosphatase) was found in other studies ${ }^{16,37}$, but no change in levels of CTX, OPG, and RANKL $^{37}$. Arends, et al, however, showed an increase in bone-specific alkaline phosphatase (bone formation marker), but also a decrease in serum collagen telopeptide (bone resorption marker) ${ }^{18}$. It is not clear why we did not find changes in the investigated bone turnover markers; it could be related to methodological errors (samples were not taken in a fasting state), type of TNF- $\alpha$ blocker, or type of the measured bone turnover markers. However, to date, the results are conflicting and the value of bone turnover markers is still not fully elucidated, especially in clinical practice ${ }^{38}$.

Interestingly, despite ETN, the radiological damage increased significantly over time. This is confirmed by other studies with TNF blockers, including ETN, which showed no delay in radiological progression in $\mathrm{AS}^{14,39}$. Kang, et al ${ }^{40}$ wrote about the "paradoxical effects" of TNF inhibitors on $\mathrm{BMD}$ and radiographic progression in AS because they also found an increase in BMD in combination with radiographic progression of the spine, as we did, although they did not study VFx in combination with radiological progression. Maksymowych, et al hypothesized that early inflammatory lesions resolve after treatment with TNF blockers before the induction of reparative changes, whereas in more mature inflammatory lesions (visible on magnetic resonance imaging as focal fat infiltration that reflects postinflammatory tissue), new bone will be formed. New bone will be formed once the signaling pathways have been activated (through downregulation of Dickkopf-1, which upregulates the Wingless pathway) ${ }^{40,41,42}$. Our study population consisted of patients with highly active disease and a long disease duration. It could be that the resolution of inflammation in these more mature lesions following ETN treatment may have caused the ongoing process of new bone formation.
There are no other studies, to our knowledge, that have investigated the effects of ETN on BMD, the occurrence of VFx, and radiological progression in combination with bone turnover markers. These factors form a very clinically relevant combination of outcome measures. However, there are some potential limitations. First, our study is an observational cohort study and no control group was available. Further, the limited size of this cohort $(n=49)$ is a potential limitation. Nevertheless, this number is higher than other studies $^{17,30,40}$ and the results are clear enough to show the challenges we are facing on this topic. Also, the duration of our study is limited by 2 years and the measurements of the biomarkers are performed within a maximum treatment duration of 1 year. However, it was to be expected that changes in biomarkers would have occurred the first year of ETN treatment, because it is known to have a strong and early effect on disease activity and subsequently on bone turnover markers, as has been shown in $\mathrm{RA}^{13}$. Finally, 3 patients used bisphosphonates. This has not influenced the outcomes of our study because the patients had already used bisphosphonates for more than 3 years, and the results including these patients were not significantly different from when they were excluded (results not shown).

Our prospective cohort study showed that after 2 years of TNF- $\alpha$ blocking therapy with ETN, BMD of the hip and spine increases, but also both the number and severity of VFx. Also, the radiological damage, including the thoracic spine, increased significantly. We showed that increasing BMD does not necessarily increase bone quality. The favorable bonepreserving effect is accompanied by unfavorable outcomes on VFx and radiological damage, suggesting both a lack of increase in bone strength and also a further ankylosis of the spine. More attention and research is needed to investigate the aspects of bone quality in patients with AS. The thoracic spine should not be overlooked as an important site of VFx.

\section{REFERENCES}

1. El Maghraoui A. Osteoporosis and ankylosing spondylitis. Joint Bone Spine 2004;71:291-5.

2. Karberg K, Zochling J, Sieper J, Felsenberg D, Braun J. Bone loss is detected more frequently in patients with ankylosing spondylitis with syndesmophytes. J Rheumatol 2005;32:1290-8.

3. van der Weijden MA, Claushuis TA, Nazari T, Lems WF, Dijkmans BA, van der Horst-Bruinsma IE. High prevalence of low bone mineral density in patients within 10 years of onset of ankylosing spondylitis: a systematic review. Clin Rheumatol 2012;31:1529-35.

4. Will R, Palmer R, Bhalla AK, Ring F, Calin A. Osteoporosis in early ankylosing spondylitis: a primary pathological event? Lancet 1989;2:1483-5.

5. Donnelly S, Doyle DV, Denton A, Rolfe I, McCloskey EV, Spector TD. Bone mineral density and vertebral compression fracture rates in ankylosing spondylitis. Ann Rheum Dis 1994;53:117-21.

6. Geusens P, Vosse D, van der Linden S. Osteoporosis and vertebral fractures in ankylosing spondylitis. Curr Opin Rheumatol 2007;19:335-9.

7. van der Weijden MA, van der Horst-Bruinsma IE, van Denderen JC, Dijkmans BA, Heymans MW, Lems WF. High frequency of vertebral fractures in early spondylarthropathies. Osteoporos Int 2012;23:1683-90 
8. Prieto-Alhambra D, Muñoz-Ortego J, De Vries F, Vosse D, Arden NK, Bowness P, et al. Ankylosing spondylitis confers substantially increased risk of clinical spine fractures: a nationwide case-control study. Osteoporos Int 2015;26:85-91.

9. Gratacós J, Collado A, Filella X, Sanmartí R, Cañete J, Llena J, et al. Serum cytokines (IL-6, TNF-alpha, IL-1 beta and IFN-gamma) in ankylosing spondylitis: a close correlation between serum IL-6 and disease activity and severity. Br J Rheumatol 1994;33:927-31.

10. Gratacós J, Collado A, Pons F, Osaba M, Sanmartí R, Roqué M, et al. Significant loss of bone mass in patients with early, active ankylosing spondylitis: a followup study. Arthritis Rheum 1999;42:2319-24.

11. Sambrook P. Tumour necrosis factor blockade and the risk of osteoporosis: back to the future. Arthritis Res Ther 2007;9:107.

12. Seriolo B, Paolino S, Sulli A, Ferretti V, Cutolo M. Bone metabolism changes during anti-TNF-alpha therapy in patients with active rheumatoid arthritis. Ann N Y Acad Sci 2006;1069:420-7.

13. Vis M, Havaardsholm EA, Haugeberg G, Uhlig T, Voskuyl AE, van de Stadt RJ, et al. Evaluation of bone mineral density, bone metabolism, osteoprotegerin and receptor activator of the NFkappaB ligand serum levels during treatment with infliximab in patients with rheumatoid arthritis. Ann Rheum Dis 2006;65:1495-9.

14. van der Heijde D, Landewé R, Einstein S, Ory P, Vosse D, Ni L, et al. Radiographic progression of ankylosing spondylitis after up to two years of treatment with etanercept. Arthritis Rheum 2008;58:1324-31.

15. van der Heijde D, Landewé R, Baraliakos X, Houben H, van Tubergen A, Williamson P, et al; Ankylosing Spondylitis Study for the Evaluation of Recombinant Infliximab Therapy Study Group. Radiographic findings following two years of infliximab therapy in patients with ankylosing spondylitis. Arthritis Rheum 2008;58:3063-70.

16. Visvanathan S, van der Heijde D, Deodhar A, Wagner C, Baker DG, Han J, et al. Effects of infliximab on markers of inflammation and bone turnover and associations with bone mineral density in patients with ankylosing spondylitis. Ann Rheum Dis 2009;68:175-82.

17. Marzo-Ortega H, McGonagle D, Haugeberg G, Green MJ, Stewart SP, Emery P. Bone mineral density improvement in spondyloarthropathy after treatment with etanercept. Ann Rheum Dis 2003;62:1020-1.

18. Arends S, Spoorenberg A, Houtman PM, Leijsma MK, Bos R, Kallenberg CG, et al. The effect of three years of TNFa blocking therapy on markers of bone turnover and their predictive value for treatment discontinuation in patients with ankylosing spondylitis: a prospective longitudinal observational cohort study. Arthritis Res Ther 2012;14:R98.

19. van der Linden S, Valkenburg HA, Cats A. Evaluation of diagnostic criteria for ankylosing spondylitis. A proposal for modification of the New York criteria. Arthritis Rheum 1984;27:361-8.

20. Assessment of fracture risk and its application to screening for postmenopausal osteoporosis. Report of a WHO Study Group [review]. World Health Organ Tech Rep Ser 1994;843:1-129.

21. Genant HK, Wu CY, van Kuijk C, Nevitt MC. Vertebral fracture assessment using a semiquantitative technique. J Bone Miner Res 1993;8:1137-48.

22. Creemers MC, Franssen MJ, van't Hof MA, Gribnau FW, van de Putte LB, van Riel PL. Assessment of outcome in ankylosing spondylitis: an extended radiographic scoring system. Ann Rheum Dis 2005;64:127-9.

23. Baraliakos X, Listing J, Rudwaleit M, Sieper J, Braun J. Development of a radiographic scoring tool for ankylosing spondylitis only based on bone formation: addition of the thoracic spine improves sensitivity to change. Arthritis Rheum 2009;61:764-71.

24. Garrett S, Jenkinson T, Kennedy LG, Whitelock H, Gaisford P, Calin A. A new approach to defining disease status in ankylosing spondylitis: the Bath Ankylosing Spondylitis Disease Activity Index. J Rheumatol 1994;21:2286-91.

25. Calin A, Garrett S, Whitelock H, Kennedy LG, O'Hea J, Mallorie P, et al. A new approach to defining functional ability in ankylosing spondylitis: the development of the Bath Ankylosing Spondylitis Functional Index. J Rheumatol 1994;21:2281-5.

26. Jenkinson TR, Mallorie PA, Whitelock HC, Kennedy LG, Garrett SL, Calin A. Defining spinal mobility in ankylosing spondylitis (AS). The Bath AS Metrology Index. J Rheumatol 1994;21:1694-8.

27. Braun J, Pham T, Sieper J, Davis J, van der Linden S, Dougados M, et al; ASAS Working Group. International ASAS consensus statement for the use of anti-tumour necrosis factor agents in patients with ankylosing spondylitis. Ann Rheum Dis 2003; 62:817-24.

28. Kawai VK, Stein CM, Perrien DS, Griffin MR. Effects of anti-tumor necrosis factor a agents on bone. Curr Opin Rheumatol 2012;24:576-85

29. Maillefert JF, Aho LS, El Maghraoui A, Dougados M, Roux C. Changes in bone density in patients with ankylosing spondylitis: a two-year follow-up study. Osteoporos Int 2001;12:605-9.

30. Allali F, Breban M, Porcher R, Maillefert JF, Dougados M, Roux C. Increase in bone mineral density of patients with spondyloarthropathy treated with anti-tumour necrosis factor alpha. Ann Rheum Dis 2003;62:347-9.

31. Kang KY, Lee KY, Kwok SK, Ju JH, Park KS, Hong YS, et al. The change of bone mineral density according to treatment agents in patients with ankylosing spondylitis. Joint Bone Spine 2011; 78:188-93

32. Haroon NN, Sriganthan J, Al Ghanim N, Inman RD, Cheung AM. Effect of TNF-alpha inhibitor treatment on bone mineral density in patients with ankylosing spondylitis: a systematic review and meta-analysis. Semin Arthritis Rheum 2014;44:155-61.

33. Lentle BC, Brown JP, Khan A, Leslie WD, Levesque J, Lyons DJ, et al; Scientific Advisory Council of Osteoporosis Canada; Canadian Association of Radiologists. Recognizing and reporting vertebral fractures: reducing the risk of future osteoporotic fractures. Can Assoc Radiol J 2007;58:27-36.

34. Donnelly E. Methods for assessing bone quality: a review. Clin Orthop Relat Res 2011;469:2128-38.

35. Marshall D, Johnell O, Wedel H. Meta-analysis of how well measures of bone mineral density predict occurrence of osteoporotic fractures. BMJ 1996;312:1254-9.

36. Bouxsein ML. Bone quality: where do we go from here? Osteoporos Int 2003;14 Suppl 5:S118-27.

37. Woo JH, Lee HJ, Sung IH, Kim TH. Changes of clinical response and bone biochemical markers in patients with ankylosing spondylitis taking etanercept. J Rheumatol 2007;34:1753-9.

38. Wheater G, Elshahaly M, Tuck SP, Datta HK, van Laar JM. The clinical utility of bone marker measurements in osteoporosis. J Transl Med 2013;11:201.

39. Senabre-Gallego JM, Santos-Ramírez C, Santos-Soler G, Salas-Heredia E, Sánchez-Barrioluengo M, Barber X, et al. Long-term safety and efficacy of etanercept in the treatment of ankylosing spondylitis. Patient Prefer Adherence 2013;7:961-72.

40. Kang KY, Ju JH, Park SH, Kim HY. The paradoxical effects of TNF inhibitors on bone mineral density and radiographic progression in patients with ankylosing spondylitis. Rheumatology 2013;52:718-26.

41. Maksymowych WP. Disease modification in ankylosing spondylitis. Nat Rev Rheumatol 2010;6:75-81.

42. Maksymowych WP, Morency N, Conner-Spady B, Lambert RG. Suppression of inflammation and effects on new bone formation in ankylosing spondylitis: evidence for a window of opportunity in disease modification. Ann Rheum Dis 2013;72:23-8. 